\title{
Primary lymphosarcoma of the lung
}

\author{
R. L. HUR T and W. P. U. KEN NEDY \\ Department of Thoracic Surgery, North Middlesex Hospital, Edmonton, London N18, \\ and Essex County Hospital, Colchester
}

\begin{abstract}
Hurt, R. L. and Kennedy, W. P. U. (1974). Thorax, 29, 258-261. Primary lymphosarcoma of the lung. A case report of lymphosarcoma of the lung in a woman aged 69 years. Middle lobectomy was carried out and the diagnosis was made only on subsequent histological examination of the resected lobe. Abnormal immunoglobulins were present in the blood both before operation and one-and-a-half years later, at which time there was a local recurrence.
\end{abstract}

\section{CASE REPORT}

I.B. aged 69 years gave a seven months' history of increasing cough and mucoid sputum, together with increasing lethargy and recent weight loss. She had smoked 5 to 10 cigarettes daily for many years. A chest radiograph (Fig. 1) showed a collapseconsolidation of the middle lobe and a bronchoscopy revealed slight narrowing of the middle lobe bronchus.

Thoracotomy was carried out in August 1970, the presumed diagnosis being a bronchial carcinoma. $A t_{\rightarrow}^{\stackrel{\rho}{5}}$ operation the middle lobe was found to be uniformly solid and of rubbery consistency. The appearances. were not those of a carcinoma and there was no glandular enlargement. There were numerous ad-乏 hesions to the upper and lower lobes. A middle lobec- $\frac{\partial}{0}$ tomy was performed without undue difficulty. Her@ postoperative course was uneventful and she wasळ discharged from hospital after two weeks.

Examination of the resected lobe showed that most $\overrightarrow{\bar{B}}$
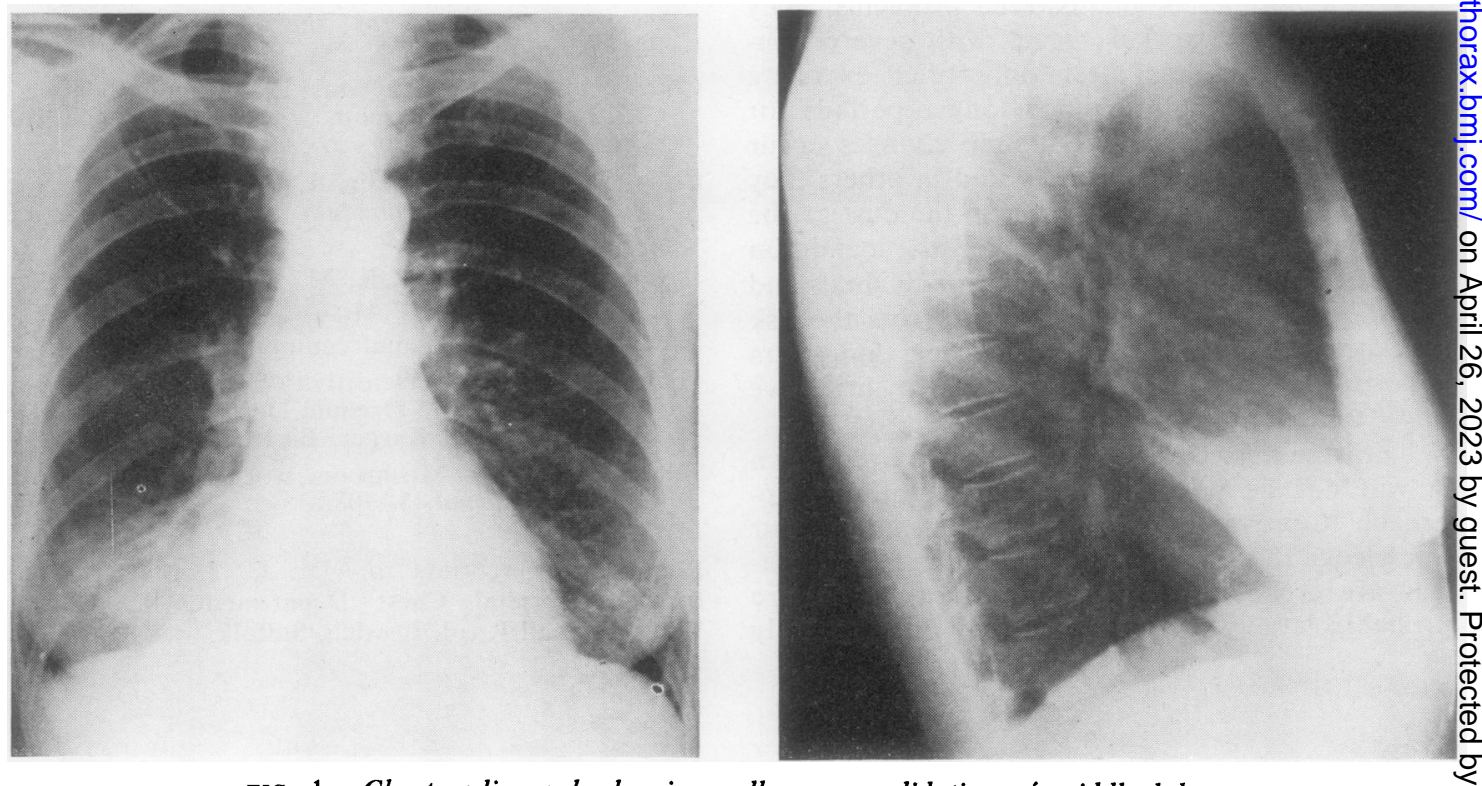

FIG. 1. Chest radiograph showing collapse-consolidation of middle lobe. 
of it was replaced by solid, yellowish-white tissue, closely approaching the pleural surface. Histologically the appearances were those of a lymphocytic lymphosarcoma. The tumour was composed of a uniform population of lymphoid cells with small nucleoli (Figs. 2 and 3). At the periphery the cells infiltrated the alveolar walls (Fig. 4) but more centrally they filled the alveoli, producing a solid mass, and infiltrated the walls of bronchioles and bronchi (Fig. 3). There was no involvement of any of the lymph nodes.

Plasma protein estimation before operation showed a total protein of $8.6 \mathrm{~g} \%$ and electrophoresis showed the presence of an abnormal IgM fraction which reacted with Bence Jones Lambda antisera only. Blood count was normal.

A year-and-a-half later after operation a repeat electrophoresis examination again showed the abnormal IgM fraction at a level of $4,250 \mathrm{mg} \%$ (normal 50-110 mg\%). Clinical examination showed no sign of any recurrence of the tumour although a chest radiograph showed a little increase in the right basal shadowing.

Two-and-a-half years after operation her general condition began to deteriorate following the onset of epigastric pain, anorexia, and episodes of vomiting. The chest radiograph was virtually unchanged but a barium meal showed a large gastric ulcer on the posterior wall of the stomach. The ESR was considerably raised at $137 \mathrm{~mm} /$ hour (Westergren) and there was a marked increase in the abnormal IgM immunoglobulin found previously $(5,200 \mathrm{mg} \%)$. A repeat bronchoscopy showed little abnormality; the bronchial mucosa on the right side was slightly oedematous but no obstructive lesion was seen. A bronchial biopsy showed some plasma cell and lymphocytic infiltration in the submucosa. Cytological examination of the sputum showed many free nuclei, of the size of a lymphocyte, with marked clumping of chromatin, suspicious of lymphosarcoma origin.

The possibility of a subphrenic extension of the lymphosarcoma being the cause of her loss of energy and loss of weight was considered. However, the patient declined gastroscopy and she was considered unfit for lymphangiography. It was decided to treat the gastric ulcer as a benign condition and she improved symptomatically on medical treatment. A repeat barium meal six weeks later, however, showed no change in the size of the ulcer.

In view of the radiographic and cytological evidence for a local recurrence of lymphosarcoma in the right lung, quadruple therapy was instituted 29 months after her operation. She received prednisolone, $10 \mathrm{mg}$ four times daily, and cyclophosphamide, $50 \mathrm{mg}$ twice daily for 14 days, together with mustine hydrochloride, $10 \mathrm{mg}$, and vincristine, $2 \mathrm{mg}$ on the first and eighth days, by intravenous infusion. Twelve days after the completion of this treatment a severe melaena occurred and, despite intensive medical treatment, there was a fairly rapid deterioration in her general condition leading to death. It was thought that the gastric haemorrhage may have been precipitated by

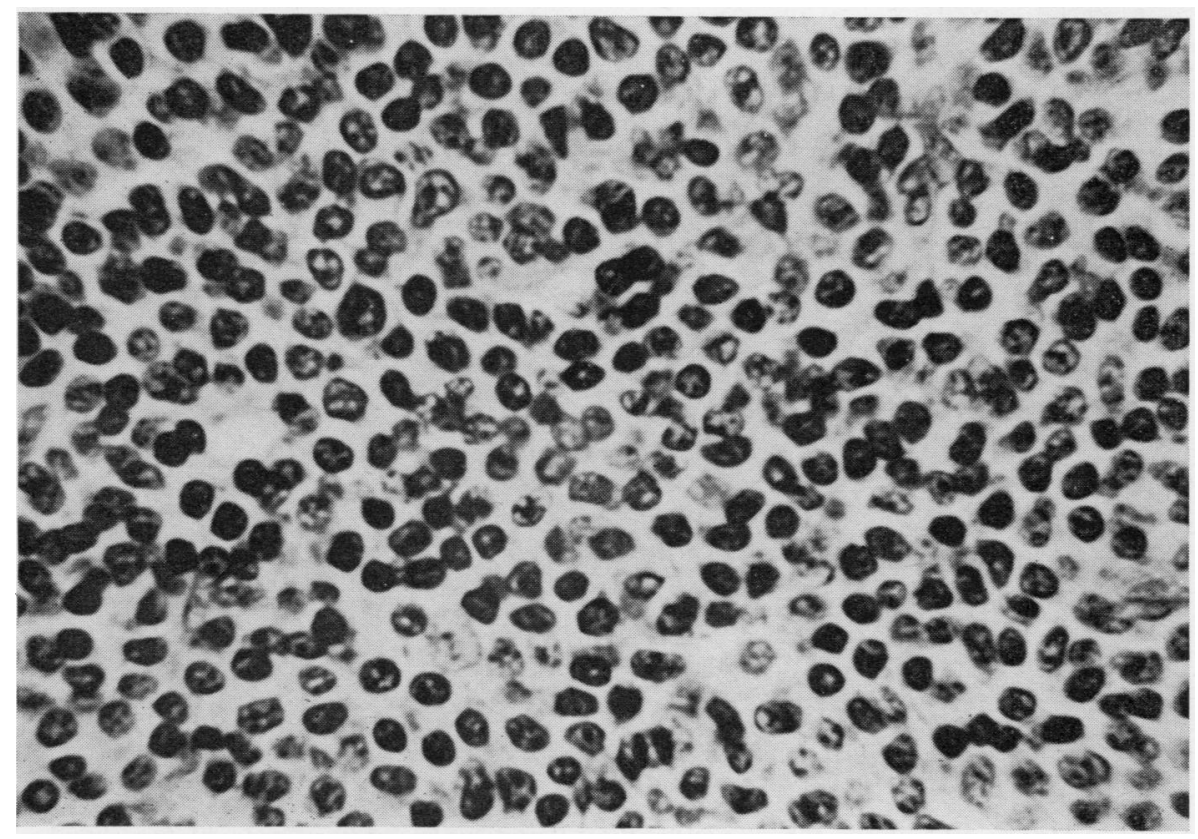

FIG. 2. Centre of tumour showing the uniformity of the cellular infiltrate ( $H$ and $E \times 690$ ). 


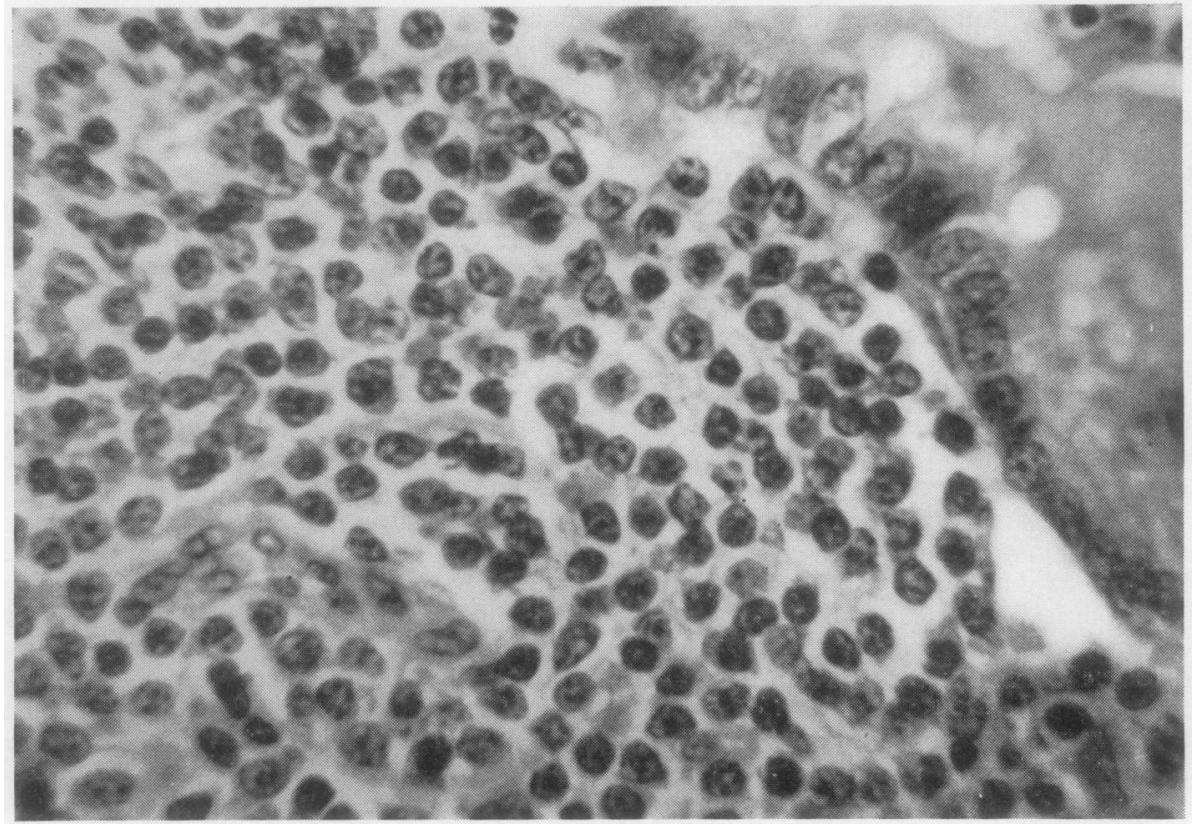

FIG. 3. Bronchiole infiltrated by uniform lymphoid cells, many of which have small nucleoli $(H$ and $E \times 690)$.

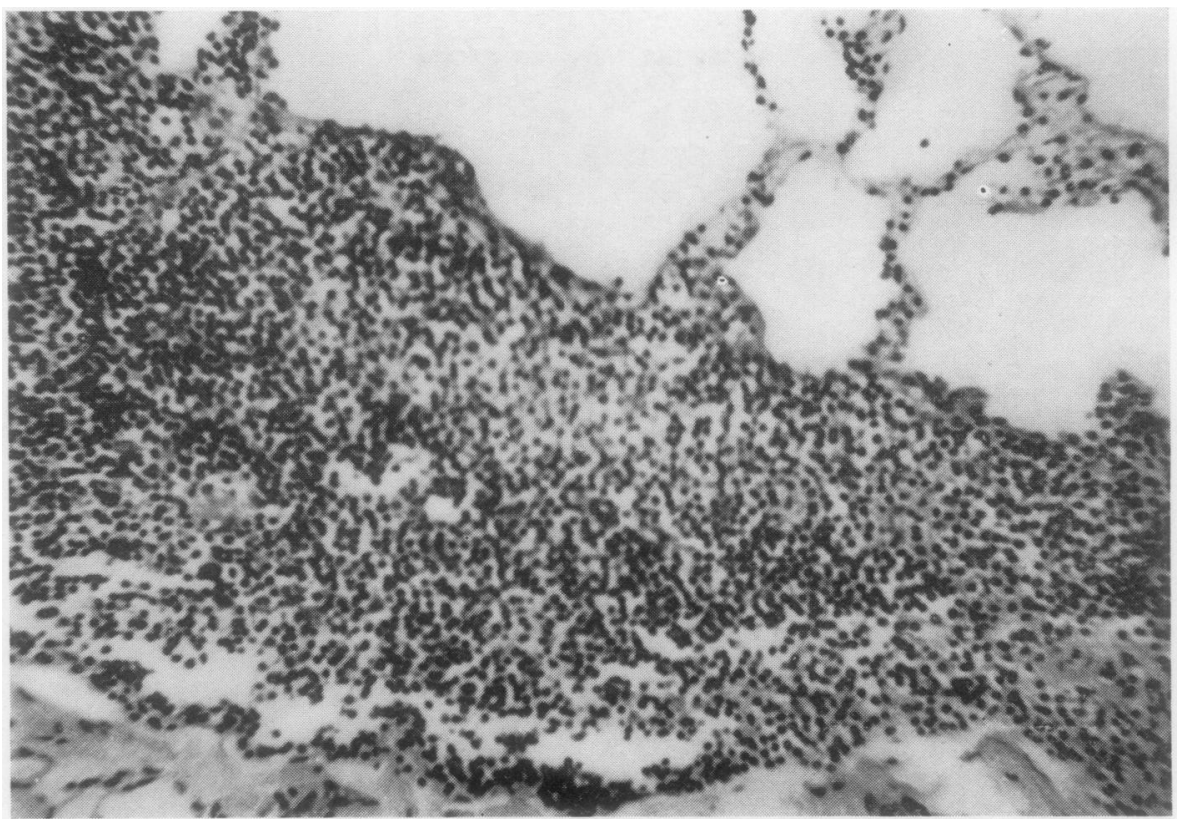

FIG. 4. Margin of tumour showing interstitial lymphocytic infiltration involving alveolar walls $(H$ and $E \times 170)$. 
the prednisolone incorporated in the quadruple therapy.

Necropsy showed a gross recurrence of the lymphosarcoma in the right upper and lower lobes, together with spread to the mediastinal glands. There was a large chronic ulcer $(5 \times 2.5 \times 2.5 \mathrm{~cm})$ in the posterior wall of the stomach penetrating into the pancreas. There was no evidence of lymphosarcoma in this ulcer or elsewhere in the body.

\section{DISCUSSION}

Lymphosarcoma of the lung has been well reviewed by Rees (1973), who analysed seven cases at the Brompton Hospital, London during the last 20 years. The reasons for reporting this patient are to record another case of a very rare disease, and to emphasize the association of this condition with abnormal immunoglobulins. Under certain conditions the cells of malignant lymphomas are capable of synthesizing abnormal proteins. These will affect the immunological mechanisms of the body and occasionally lead to an acquired haemolytic anaemia (Rappaport and Johnson, 1955). It is interesting that the immunoglobulin level in this patient was still considerably raised one-and-a-half years after operation, at a time when a local recurrence of the tumour had occurred.
One of the notable features of lymphosarcoma of the lung (and indeed of other organs) is the absence of mediastinal lymph node involvement (Havard, Nichols, and Stansfeld, 1962). This is surprising in view of the locally invasive nature of the tumour. In the case reported, there was no lymph node involvement at operation, though there was at necropsy over two years later.

We are most grateful to Dr. W. J. Harrison and Dr. K. A. D. Turk for the histological report and photographs and to Dr. J. B. Penfold for the necropsy report.

\section{REFERENCES}

Havard, C. W. H., Nichols, J. B., and Stansfeld, A. G. (1962). Primary lymphosarcoma of the lung. Thorax, 17, 190.

Rappaport, H. and Johnson, F. B. (1955). Intracellular protein resembling Russell bodies in malignant lymphomas associated with acquired hemolytic anemia. Blood, 10, 132.

Rees, G. M. (1973). Primary lymphosarcoma of the lung. Thorax, 28, 429.

Requests for reprints to: R. L. Hurt, F.R.C.S., Department of Thoracic Surgery, North Middlesex Hospital, Edmonton, London N18. 